\title{
RISK REDUCTION OF THE SUPPLY CHAIN THROUGH POOLING LOSSES IN CASE OF BANKRUPTCY OF SUPPLIERS USING THE BLACK-SCHOLES-MERTON PRICING MODEL
}

\author{
RAUL VALVERDE* and MALLESWARA TALLA \\ Department of Decision Sciences and MIS, Concordia University, \\ 1455 de Maisonneuve Blvd West, Montreal, Quebec, Canada \\ *E-mail: rvalverde@jmsb.concordia.ca
}

\begin{abstract}
In recession times, slower demand, shrunk liquidity, and increasing pressure on cost can lead to bankruptcy of suppliers. The risks due to supplier bankruptcy include (a) losses due to supply chain disruption, (b) delayed or stopped finished goods shipments, (c) difficulty in finding cost-effective alternate suppliers and sourcing contracts, (d) emergency procurements, (e) loss of reputation and market share loss, etc. Bankruptcy models can be used to estimate the probability that a supplier may go bankruptcy, and a level of probability can be established that triggers the risks. This paper uses the Black-Scholes-Merton option pricing model for estimating the probability of bankruptcy of supplier by extracting and examining the riskiness in stock market price of supplier. The paper uses the pooling arrangements among companies that source from multiple suppliers as a way to reduce the risk due to supplier bankruptcy.
\end{abstract}

\section{Introduction}

In recent times, companies are increasingly forming global supply chains and favoring global sourcing practices for lowering the purchase prices. While the global sourcing truly offered the expected benefits in the short run, it increased the risk of facing several challenges in the long run. One of the major issues is the supplier financial distress leading to supplier bankruptcy due to slower demand, shrunk liquidity, and increasing pressure on cost. The risks due to supplier bankruptcy include (a) losses due to supply chain disruption, (b) delayed or stopped finished goods shipments, (c) difficulty in finding cost-effective alternate suppliers and sourcing contracts, (d) emergency procurements, (e) loss of reputation and market share loss, etc. In summary, if a supplier becomes bankrupt, that firm may not be able to meet its entire customer requirements in the short-term, and will 
not meet any customer requirements if it eventually goes out of business (see Zsidisin and Wagner ${ }^{7}$ ). A firm is obliged to evaluate the financial viability of suppliers in order to avoid the consequences of supplier default, insolvency, or bankruptcy (see Milne ${ }^{3}$ and Wagner and Johnson ${ }^{6}$ ).

The good tools for financial evaluation are the bankruptcy models, as these can be used for estimating the probability that a supplier may go bankrupt, and a level of probability can be established that triggers the risks. This paper uses the Black-Scholes-Merton option pricing model $^{1}$ for estimating the probability of bankruptcy of supplier by extracting and examining the riskiness in stock market price of supplier. The model assumes: maturity of liabilities equals one year; the dividend rate is based on the sum of common dividends, preferred dividends, and interest expense; call option equation has been modified to account for the fact that shareholders receive common dividends. ${ }^{1}$

In order to minimize the risk of bankruptcy among suppliers, the paper proposes the use of a pooling arrangement among companies. In a pooling arrangement, every participant agrees to share losses equally, each paying an average loss. The arrangement does not change the expected loss but reduces uncertainty because the variance decreases. This makes the losses due to supplier bankruptcy become more predictable since the maximum probable loss declines and the distribution of costs becomes more symmetric. The predictability increases with the number of participants and decreases with correlation in losses. Previously, pooling arrangements have been used in supply chains for inventory management for the reduction of demand variability that can lead to a reduction of safety stock and average inventory, ${ }^{4}$ however, this paper combines the use of bankruptcy prediction models and pool arrangements for risk reduction in the supply chain. This pool arrangement methodology could be used as a tool for the preparation of insurance policies that can be sold to companies in order to protect them against supplier bankruptcy.

\section{Black-Scholes-Merton Option Pricing Model}

The bankruptcy losses for suppliers are based on the Black-Scholes-Merton option pricing model1. With this model, a company is defined as being in bankruptcy if its corporate value shown by aggregate market value falls short of its amount of debt. ${ }^{1}$ The model captures the likelihood that the values of firms assets will decline to such an extent that the firm will be unable to repay its debts. ${ }^{1}$

Equity can be viewed as a call option on the value of the firm's assets. 
The strike price of the call option is equal to the face value of the firm's liabilities and the option expires at time $\mathrm{T}$ when the debt matures1.

The equation for valuing equity as a call option on the value of the firm's assets is given in Eq. (1) below. This equation is modified for dividends and reflects that the stream of dividends paid by the firm accrue to the equity holders.

The BSM equation is given by (see Wagner and Johnson ${ }^{6}$ ):

$$
V_{E}=V_{A} \mathrm{e}^{-\delta T} N\left(d_{1}\right)-X \mathrm{e}^{-r T} N\left(d_{2}\right)+\left(1-\mathrm{e}^{-\delta T}\right) V_{A}
$$

where $N($.$) represents the cumulative distribution function of standard nor-$ mal random variable and $\mathrm{d} 1$ and $\mathrm{d} 2$ are given by:

$$
\begin{aligned}
& d_{1}=\frac{\ln \left(\frac{V_{A}}{X}\right)+\left(r-\delta+\frac{\sigma_{2}^{2}}{2}\right) T}{\sigma_{A} \sqrt{T}} \\
& d_{2}=d_{1}-\sigma_{A} \sqrt{T}=\frac{\ln \left(\frac{V_{A}}{X}\right)+\left(r-\delta-\frac{\sigma_{2}^{2}}{2}\right) T}{\sigma_{A} \sqrt{T}}
\end{aligned}
$$

where $V_{E} \equiv V_{E}(t)$ is the current market value of equity, $V_{A} \equiv V_{A}(t)$ is the current (at time $t$ ) market value of assets, $X$ is the face value of debt maturing at time $T, r$ is the continuously-compounded risk-free rate, $\delta$ is the continuous dividend rate $\sigma_{A}$ is the standard deviation of asset returns.

Under the BSM model, the probability of bankruptcy is simply the probability that the market value of assets, $V_{A}$ is less than the face value of the liabilities, $\mathrm{X}$, at time T. The BSM model assumes that the natural log of future asset values is normally distributed. The probability of bankruptcy is a function of the distance between the current value of the firm's assets and the face value of its liabilities, adjusted for the expected growth in asset values relative to asset volatility.

As shown in McDonald, ${ }^{2}$ the probability of bankruptcy can be calculated as:

$$
N\left(\frac{\ln \left(\frac{V_{A}}{X}\right)+\left(\mu-\delta+\frac{\sigma_{2}^{2}}{2}\right) T}{\sigma_{A} \sqrt{T}}\right)
$$

where $\mu$ is the continuously-compounded expected return on assets. Hillegeist et al. ${ }^{5}$ provided the SAS code for the estimation of $V_{A}$ and $\sigma_{A}$ by simultaneously solving the BSM equation (1) and the optimal hedge equation given by 


$$
\sigma_{E}=\frac{V_{A} \mathrm{e}^{-\delta t} N\left(d_{1}\right) \sigma_{A}}{V_{E}}
$$

through iterative process. These values are then used to estimate $\mu$ from the following formula

$$
\mu=\max \left(\frac{V_{A}(t)-V_{A}(t-1)+\text { dividents }}{V_{A}(t-1)}, r\right)
$$

where dividends in the above equation represent the sum of the common and preferred dividends declared during the year. This in turn can finally be used to calculate the probability of bankruptcy.

The basic idea for estimating the probability of a supplier company bankruptcy is to recognize the stock price movement pattern of the supplier company, and evaluate the historic events information, which is available to public via company press meets, market focus, etc. The procedure for extracting such information was developed by Hillegeist et al. ${ }^{5}$ This paper describes the reasoning behind using stock prices, as opposed to accounting data, to extract the probability of supplier bankruptcy estimates as well as the methodological steps and assumptions behind the estimates.

According to option-pricing theories (see $\mathrm{McDonald}^{2}$ ), a market-based measure, that is called Black-Sholes-Model probability of bankruptcy (BSM-PB), should use all available information about the probability of bankruptcy. ${ }^{5}$ The BSM-PB contains relatively more information than just the Score variables used traditionally for bankruptcy prediction, however the accounting measures will not be incrementally informative to BSM-PB. Hillegeist et al. ${ }^{5}$ tested the validity of these implications using a large sample consisting of 65,960 firm-year observations including 516 bankruptcies during the 1979-1997 period. They found that BSM-PB has relatively more explanatory power than either of the two Scores, even when the Scores are decomposed to reflect industry differences or annual changes.

The model assumes that volatility is a crucial variable in bankruptcy prediction since it captures the likelihood that the values of firms assets will decline to such an extent that the firm will be unable to repay its debts. Equity can be viewed as a call option on the value of the firm's assets. The strike price of the call option is equal to the face value of the firm's liabilities and the option expires at time $\mathrm{T}$ when the debt matures. 


\section{Risk Reduction through Pooling Independent Losses}

A risk pool is one of the forms of risk management practiced in insurance. Pooling arrangements do not change a company's expected loss, but reduce the uncertainty (standard deviation) of a loss. Risk pooling arrangements make each participant's loss more predictable ( Zsidisin and Wagner ${ }^{7}$ ).

Correlation analysis is very important in pooling arrangements. A positive correlation in losses is less desirable than null correlation (uncorrelated losses) in the context of risk management. While a positive correlation in losses reduces the extent to which risk pooling lowers the standard deviation of losses, null correlation in losses increase it. The concept of pooling losses has been used in supply chain (see Milne ${ }^{3}$ ). Risk pooling suggests that demand variability is reduced if one aggregates demand across locations because as demand is aggregated across different locations, it becomes more likely that high demand from one customer will be offset by low demand from another. This reduction in variability allows a decrease in safety stock and therefore reduces average inventory, this suggests that the use centralized warehouses would be able to reduce inventory costs as it reduces safety stock but this benefit will decrease as the correlation between demands demanding inventory becomes positive (see Milne ${ }^{3}$ ).

The expected loss and variance for a company $C$ associated with $M$ suppliers, due to supplier bankruptcy can be estimated by

$$
\bar{L}_{C}=\sum_{i=1}^{M} L_{i} P_{i},
$$

and

$$
\sigma_{C}^{2}=\sum_{i=1}^{M}\left(L_{i}-\bar{L}_{C}\right)^{2} P_{i},
$$

respectively, where $L_{i}$ is the loss of a company due to supplier bankruptcy, $P_{i}$ is the probability of bankruptcy of a supplier.

In the context of the proposed research, each firm in the pool is willing to share the losses generated due to bankruptcy of suppliers. The research will show how the mechanism can be used to reduce the standard deviation of the losses associated with risk of losses.

\section{Illustration of the Methods on Real Data}

In order to find the probability of bankruptcy, a research was conducted by selecting 23 companies that trade in the stock market and publish their 
financial statements. The BSM model has been used for calculating the probability of bankruptcy for these 23 firms for the first quarter for the year 2000. A scenario of two companies that have three suppliers each was generated and the losses due to bankruptcy for each supplier were pooled among the two companies and the expected loss and standard deviation of losses calculated by pooling losses. The objective of the research is to show that the risk pooling contract minimizes the risk exposure.

A SAS program generated by Hillegeist et al. ${ }^{5}$ was used to calculate the probability of bankruptcy. The calculation was performed in three steps. In the first step, the values of $V_{A}$ and $\sigma_{A}$ were estimated by simultaneously solving the call option B-S-M equation (Eq. (1)) and the optimal hedging equation (Eq. (4)).

In the initial step, $V_{E}$ was set equal to the total market value of equity based on the closing price at the end of the firm's fiscal year, $\sigma_{E}$ was computed using daily return data from the Center for Research in Security Prices database (http://www.crsp.com) over the entire fiscal year. The strike price $X$ was set equal to the book value of total liabilities, $T$ was taken to be one year, and $r$ was set at the one-year treasury bill rate. The dividend rate, $\delta$, was the sum of the prior year's common and preferred dividends divided by the approximate market value of assets, which is defined as total liabilities plus the market value of equity.

In the second step, the expected market return on assets, $\mu$, was calculated based on the actual return on assets during the previous year and with the help of Eq. (6). This process is based on the estimates of VA that were computed in the previous step.

Finally, the values for $V_{A}, \sigma_{A}, \delta, T, X$ and $\mu$ were used to calculate the probability of bankruptcy for each firm-year via Eq. (4). To do this, the value inside the parentheses in Eq. (4) was first calculated to then determine the probability of bankruptcy corresponding to this value using the standard normal distribution.

Table 1 presents the probability of bankruptcy for the 23 companies based on the first quarter of the year 2000. The same table displays the values of $V_{A}$ and $\sigma_{A}$ calculated in the first step.

The scenario used for this analysis assumes two companies with three suppliers each. The loss due to bankruptcy for each supplier is assumed to be constant and estimated to be $\$ 5000$, which include losses due to supply chain disruption, delayed or stopped finished goods shipments, difficulty in finding cost-effective alternate suppliers and sourcing contracts, emergency procurements, loss of reputation and market share among the 
Table 1. Probabilities of bankruptcy for suppliers for Year 2000 and Quarter 1.

\begin{tabular}{|c|c|c|c|c|}
\hline Supplier company & GVKey & $V_{A}$ & $\sigma_{A}$ & $\begin{array}{c}\text { Probability } \\
\text { of } \\
\text { bankruptcy }\end{array}$ \\
\hline AAR CORP & 1004 & 708.5085 & 0.263461 & .02170124 \\
\hline ADC TELECOMMUNICATIONS INC & 1013 & 10381.02 & 0.645216 & $9.22 \mathrm{E}-08$ \\
\hline ALPHARMA INC & 1034 & 1522.568 & 0.237037 & 0.00142876 \\
\hline UNITED DOMONION INDUSTRIES & 1036 & 2076.659 & 0.118494 & 0.0002026 \\
\hline AMC ENTERTAINMENT INC & 1038 & 1167.491 & 0.066569 & 0.10188689 \\
\hline AMR CORP/DE & 1045 & 21949.29 & 0.094827 & 0.00510627 \\
\hline CECO ENVIRONMENTAL CORP & 1050 & 58.37434 & 0.421999 & 0.22111509 \\
\hline ASA BERMUDA LTD & 1062 & 176.6768 & 0.385425 & 0 \\
\hline AVX CORP & 1072 & 4321.04 & 0.651542 & 0.00019655 \\
\hline PINNACLE WEST CAPITAL & 1075 & 6719.818 & 0.099677 & $7.56 \mathrm{E}-06$ \\
\hline AARON RENTS INC & 1076 & 373.1073 & 0.285872 & .00019291 \\
\hline ABITIBI CONSOLIDATED INC & 1081 & 3063.677 & 0.06287 & .04249133 \\
\hline ABRAMS INDUSTRIES INC & 1082 & 97.4321 & 0.117798 & 0.04888238 \\
\hline ACKERLY GROUP INC & 1095 & 790.4289 & 0.196604 & 0.00072447 \\
\hline ACMAT CORP & 1097 & 101.7899 & 0.203711 & 0.18243195 \\
\hline ACME UNITED CORP & 1104 & 22.51936 & 0.452804 & 0.07257192 \\
\hline ACTION PRODUCTS INTL INC & 1109 & 6.425416 & 0.946431 & 0.20192717 \\
\hline ACTIVISION INC & 1111 & 307.8869 & 0.378032 & 0.0435724 \\
\hline RELM WIRELESS CORP & 1117 & 36.01124 & 1.057167 & 0.29516477 \\
\hline ADAMS RESOURCES \& ENERGY INC & 1121 & 342.5629 & 0.066581 & $1.50 \mathrm{E}-06$ \\
\hline AERO SYSTEMS ENGINEERING INC & 1154 & 22.2858 & 0.94807 & 0.44375006 \\
\hline ADVANCES MICRO DEVICES & 1161 & 11023.84 & 0.559808 & 0.00014882 \\
\hline ASM INTERNATIONAL NV & 1166 & 1592.034 & 0.733109 & 0.03627255 \\
\hline
\end{tabular}

Table 2. Company A's expected losses and standard deviation due to bankruptcy of suppliers.

\begin{tabular}{|l|c|r|r|}
\hline Suppliers & $\begin{array}{c}\text { Probability } \\
\text { of } \\
\text { of bankruptcy }\end{array}$ & $\begin{array}{c}\text { Loss due to } \\
\text { bankruptcy }\end{array}$ & $\begin{array}{r}\text { Supplier's } \\
\text { expected loss }\end{array}$ \\
\hline AAR CORP & 0.021701241 & 5000 & 108.51 \\
\hline ABRAMS INDUSTRIES INC & 0.048882378 & 5000 & 244.41 \\
\hline ACTION PRODUCTS INTL INC & 0.201927167 & 5000 & 1009.64 \\
\hline \multicolumn{3}{|c|}{ Expected Loss } & 1362.55 \\
\hline \multicolumn{3}{|c|}{ Standard deviation } & 1898.84 \\
\hline
\end{tabular}

possible losses. Tables 2 and 3 present the expected losses and standard deviation of companies A and B due to bankruptcy of their three suppliers, respectively.

Table 4 shows the expected losses for the pooling arrangement of the two companies. In this arrangement, losses are shared equally between companies $\mathrm{A}$ and $\mathrm{B}$. The estimates show that uncertainty represented by the standard deviation is reduced while the average loss remained unchanged 
Table 3. Company B's expected losses and standard deviation due to bankruptcy of suppliers.

\begin{tabular}{|l|c|r|r|}
\hline Suppliers & $\begin{array}{c}\text { Probability } \\
\text { of } \\
\text { of bankruptcy }\end{array}$ & $\begin{array}{r}\text { Loss due to } \\
\text { bankruptcy }\end{array}$ & $\begin{array}{r}\text { Supplier's } \\
\text { expected loss }\end{array}$ \\
\hline ASA BERMUDA LTD & 0 & 5000 & 0 \\
\hline ACKERLY GROUP INC & 0.00072447 & 5000 & 3.62 \\
\hline RELM WIRELESS CORP & 0.29516477 & 5000 & 1475.82 \\
\hline \multicolumn{3}{|c|}{ Expected Loss } & 1479.45 \\
\hline \multicolumn{3}{|c|}{ Standard deviation } & 1915.03 \\
\hline
\end{tabular}

$((1362.55+1479.45) / 2=\$ 1421)$.

Table 4. Pooling arrangement between companies A and B.

\begin{tabular}{|c|c|r|r|}
\hline Losses & $\begin{array}{c}\text { Portion of } \\
\text { pooled } \\
\text { outcome }\end{array}$ & $\begin{array}{c}\text { Probability } \\
\text { of bankruptcy }\end{array}$ & $\begin{array}{c}\text { Expected loss } \\
\text { per } \\
\text { arrangement }\end{array}$ \\
\hline 0 & 0 & 0.523023 & 0 \\
\hline 5000 & 2500 & 0.219406 & 548.51593 \\
\hline 10000 & 5000 & $1.58793 \mathrm{E}-04$ & 0.79396 \\
\hline 15000 & 7500 & 0 & 0 \\
\hline 5000 & 2500 & 0.17081 & 427.04308 \\
\hline 10000 & 5000 & 0.07165 & 358.28597 \\
\hline 15000 & 7500 & $0.1861 \mathrm{E}-05$ & 0.38896 \\
\hline 20000 & 10000 & 0 & 0 \\
\hline 10000 & 5000 & 0.004033 & 51.66552 \\
\hline 15000 & 7500 & $3.13719 \mathrm{E}-06$ & 32.51024 \\
\hline 20000 & 10000 & 0 & 0.03137 \\
\hline 25000 & 12500 & $1.50871 \mathrm{E}-04$ & 0 \\
\hline 15000 & 7500 & $6.32896 \mathrm{E}-05$ & 0.63290 \\
\hline 20000 & 10000 & $4.58051 \mathrm{E}-08$ & 0.00057 \\
\hline 25000 & 12500 & 0 & 0 \\
\hline 30000 & 15000 & Expected Loss & 1421.00 \\
\hline & & & 1601.44 \\
\hline & & Standard deviation & \\
\hline
\end{tabular}




\section{Conclusions and Future Research}

This study clearly demonstrates the usefulness of estimating the probability of bankruptcy of suppliers for managing the risk to a supply chain. The results presented show how the pooling contracts can help companies to minimize the risk of losses due to supplier bankruptcy. These pooling contracts can be managed by insurance carriers and sold to companies as supplier bankruptcy insurance. Furthermore, the pooling contracts help companies minimize the risk. Here we used a simple scenario with a pooling arrangement with two companies and three suppliers. Although this paper assumes that a company does not experience any loss while a supplier is not bankrupt, unexpected events (fluctuations in price, etc.) may amount to a certain loss. The analysis and computation of this paper can be revised to account for such factors. Moreover, the future research can include different types of risks and estimates for other types of supply chain risks, and conduct a study with multiple scenarios in order to provide more evidence that the concept can work in industry. Future work can also include a software program which can be developed for any number of supplier companies and pooling contracts with increased participation.

\section{References}

1. F. Black and M. Scholes, The Journal of Political Economy 81, 637 (1973).

2. R. McDonald, Derivative Markets (Addison Wesley, Boston, MA, 2002).

3. Richard Milne, Early Warnings in the Supply Chain, In Financial Times Europe, No. 36957, pp. 10 (2010).

4. D. Simchi-Levi, P. Kaminsky and E. Simchi-Levi, Designing $\&$ Managing the Supply Chain, second edition (McGraw Hill, New York, USA, 2003).

5. Stephen A. Hillegeist, Elizabeth K. Keating, Donald P. Cram, Kyle G. Lundstedt, Review of Accounting Studies 9, 5 (2004).

6. S. M. Wagner and J. L. Johnson, Industrial Marketing Management 33, 717 (2004).

7. G. A. Zsidisin and S. M. Wagner, Journal of Business Logistics 31, 1 (2010). 